\title{
Cancer cachexia syndrome and clinical outcome in patients with metastatic non-small cell lung cancer treated with PD-1/PD-L1 inhibitors: results from a prospective, observational study
}

\author{
Konstantinos Rounis ${ }^{1}$, Dimitrios Makrakis ${ }^{2}$, Alexandros-Pantelis Tsigkas ${ }^{3}$, Alexandra Georgiou ${ }^{3}$, \\ Nikolaos Galanakis ${ }^{4}$, Chara Papadaki ${ }^{5}$, Alexia Monastirioti ${ }^{5}$, Lambros Vamvakas ${ }^{1}$, Konstantinos Kalbakis ${ }^{1}$, \\ Nikolaos Vardakis ${ }^{1}$, Meropi Kontogianni ${ }^{3}$, Ioannis Gioulbasanis ${ }^{6}$, Dimitrios Mavroudis ${ }^{1,5}$, Sofia Agelaki ${ }^{1,5}$ \\ ${ }^{1}$ Department of Medical Oncology, University General Hospital of Heraklion, Heraklion, Crete, Greece; ${ }^{2}$ Division of Oncology, University of \\ Washington Medical School, Seattle, WA, USA; ${ }^{3}$ Department of Nutrition \& Dietetics, School of Health Sciences and Education, Harokopio \\ University, Athens, Greece; ${ }^{4}$ Department of Medical Imaging, University General Hospital, Heraklion, Crete, Greece; ${ }^{5}$ Laboratory of Translational \\ Oncology, School of Medicine, University of Crete, Heraklion, Greece; ${ }^{6}$ Department of Medical Oncology, Animus Kyanus Stavros General Clinic, \\ Larissa, Greece \\ Contributions: (I) Conception and design: S Agelaki; (II) Administrative support: None; (III) Provision of study materials or patients: K Rounis, L \\ Vamvakas, K Kalbakis, N Vardakis, S Agelaki, D Mavroudis; (IV) Collection and assembly of data: K Rounis, D Makrakis, N Galanakis, C Papadaki, \\ A Monastirioti; (V) Data analysis and interpretation: K Rounis, AP Tsigkas, A Georgiou, M Kontogianni, I Gioulbasanis, D Mavroudis, S Agelaki; (VI) \\ Manuscript writing: All authors; (VII) Final approval of manuscript: All authors. \\ Correspondence to: Konstantinos Rounis, MD. Medical Oncologist, University General Hospital of Heraklion, Crete, Greece. Email: kostas@rounis.gr.
}

Background: Cancer cachexia syndrome (CCS) is an adverse prognostic factor in cancer patients undergoing chemotherapy or surgical procedures. We performed a prospective study to investigate the effect of CCS on treatment outcomes in patients with non-oncogene driven metastatic non-small cell lung cancer (NSCLC) undergoing therapy with programmed cell death protein 1 (PD-1)/programmed death ligand 1 (PD-L1) inhibitors.

Methods: Patients were categorized as having cancer cachexia if they had weight loss $>5 \%$ in the last 6 months prior to immunotherapy (I-O) initiation or any degree of weight loss $>2 \%$ and body mass index (BMI) $<20 \mathrm{~kg} / \mathrm{m}^{2}$ or skeletal muscle index at the level of third lumbar vertebra (LSMI) $<55 \mathrm{~cm}^{2} / \mathrm{m}^{2}$ for males and $<39 \mathrm{~cm}^{2} / \mathrm{m}^{2}$ for females. LSMI was calculated using computed tomography (CT) scans of the abdomen at the beginning of I-O and every 3 months thereafter.

Results: Eighty-three patients were included in the analysis and the prevalence of cancer cachexia at the beginning of I-O was $51.8 \%$. The presence of CCS was associated with inferior response rates to ICIs $(\mathrm{P} \leq 0.001)$ and consisted an independent predictor of increased probability for developing disease progression as best response to treatment, $\mathrm{OR}=8.11$ (95\% CI: 2.95-22.40, $\mathrm{P} \leq 0.001)$. In the multivariate analysis, the presence of baseline cancer cachexia consisted an independent predictor for inferior survival, $\mathrm{HR}=2.52$ (95\% CI: $1.40-2.55, \mathrm{P}=0.002$ ). Reduction of $\mathrm{LSMI}>5 \%$ during treatment did not affect overall survival (OS; $\mathrm{P}=0.40$ ).

Conclusions: CCS is associated with reduced PD-1/PD-L1 inhibitor efficacy in NSCLC patients and should constitute an additional stratification factor in future I-O clinical trials. Further research at a translational and molecular level is required to decipher the mechanisms of interrelation of metabolic deregulation and suppression of antitumor immunity.

Keywords: Cancer cachexia; immunotherapy; PD-1/PD-L1 inhibitors; non-small cell lung cancer (NSCLC); outcome; survival; response rate

$\wedge$ ORCID: 0000-0002-6643-9855. 
Submitted Jun 03, 2021. Accepted for publication Aug 19, 2021.

doi: $10.21037 /$ tlcr-21-460

View this article at: https://dx.doi.org/10.21037/tlcr-21-460

\section{Introduction}

Immunotherapy (I-O) with immune checkpoint inhibitors (ICIs) has defined a new era in the management of patients with metastatic non-small cell lung cancer (NSCLC). However, beyond programmed death ligand 1 (PD-L1) expression levels in cancer tissues, there is a paucity of biomarkers for the prediction of outcome in patients with metastatic NSCLC treated with ICIs (1). In addition, only a small subset of NSCLC patients receiving PD-1/PDL1 inhibitors will achieve a durable clinical benefit and the underlying mechanisms that lead to primary or secondary resistance to I-O have not been elucidated thus far (2).

Cancer cachexia syndrome (CCS) is a complex metabolic syndrome characterized by weight loss, alterations in body composition and a pathophysiologic background that is defined by a perpetually sustained inflammatory process (3). CCS has a high prevalence amongst cancer patients and has been associated with adverse survival outcomes and reduced treatment efficacy (4). Furthermore, it has been estimated that it directly accounts for approximately $20 \%$ of cancerrelated mortality (5).

Beyond its well-recognized effect on host's metabolic homeostasis deregulation, CCS has been also associated with immune system dysfunction and increased susceptibility to infections (6). CCS is characterized by a composite molecular pathogenesis that involves a wide spectrum of inflammatory processes ranging from increased levels in the serum or the tumor microenvironment (TME) of certain cytokines such as tumor necrosis factor (TNF)- $\alpha$ (7), interleukins (IL)-6 (6), IL-8 (8) and growth differentiation factor (GDF)-15 (9) to increased plasma or TME concentrations of myeloid derived suppressor cells (MDSCs) (10). The vast majority of these processes have been demonstrated in experimental models to affect the Cancer-Immunity-Cycle (11) and to exert a negative effect on antitumor immunity (12-16).

Based on the aforementioned reports, we hypothesized that the activation of the cellular pathways that define CCS pathogenesis could have a negative effect on antitumor immunity, thus abrogating I-O efficacy. In order to test our hypothesis, we conducted a prospective observational study at the University Hospital of Heraklion, Crete amongst patients with metastatic NSCLC that were treated with ICIs. We present the following article in accordance with the REMARK reporting checklist (available at https:// dx.doi.org/10.21037/tlcr-21-460).

\section{Methods}

\section{Patient selection}

We prospectively collected clinical and radiological data from patients with non-oncogene driven metastatic NSCLC who received I-O either as monotherapy or in combination with chemotherapy according to ESMO guidelines (17) from 2017-2020 at the University Hospital of Heraklion, Crete. All consecutive patients that were deemed to be candidates for receiving treatment with PD-1/PD-L1 inhibitors for metastatic NSCLC were screened for inclusion in this study. Individuals with $E G F R$ mutations or $A L K$ translocations were excluded before the initial screening. EGFR mutational status was assessed using polymerase chain reaction (PCR) and $A L K$ genomic alterations were examined using immunohistochemistry (ICH) or fluorescence in situ hybridization (FISH), respectively. The study was approved from the Ethics Committee of the University Hospital of Heraklion (ID: 2644) and was conducted according to principles of the declaration of Helsinki (as revised in 2013). Written informed consent was obtained from all patients before enrollment.

\section{Cachexia assessment}

Patients were categorized as having cachexia based on the criteria set by Fearon et al. (18). These consist of body weight loss $>5 \%$ within the last 6 months or body mass index (BMI) $<20 \mathrm{~kg} / \mathrm{m}^{2}$ and any degree of weight loss $>2 \%$ or low appendicular skeletal muscle index consisted with sarcopenia and any degree of weight loss $>2 \%$.

We assessed the appendicular skeletal muscle index of the patients by measuring the skeletal muscle thickness at the level of the third lumbar vertebra by analyzing the patients' abdominal computed tomography (CT) scans before the initiation of I-O through the application of 

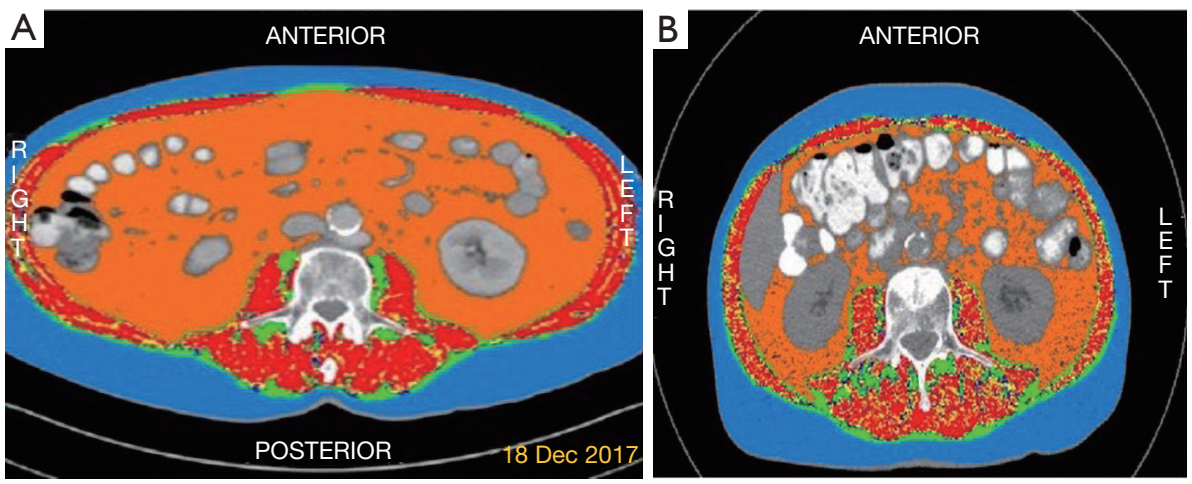

Figure 1 Tomovision analysis of the CT scans of two individuals in our cohort. (A) A male patient with baseline LSMI $=55.02 \mathrm{~cm}^{2} / \mathrm{m}^{2}$ without sarcopenia. (B) A male patient with baseline LSMI $=39.45 \mathrm{~cm}^{2} / \mathrm{m}^{2}$ consistent with sarcopenia. CT scan, computed tomography scan; LSMI, lumbar skeletal muscle index $\left(\mathrm{cm}^{2} / \mathrm{m}^{2}\right)$ (at the level of $3 \mathrm{rd}$ lumbar vertebra).

Slice-o-matic Tomovision software (sliceOmatic 5.0 Rev-9 Alberta Protocol) (Figure 1). The muscle area thickness was divided by each individual's squared height, thus creating a baseline Lumbar Skeletal Muscle Index (LSMI) that was measured in $\mathrm{cm}^{2} / \mathrm{m}^{2}$. The LSMI cut-off values (LNL: lower normal limit) used for the definition of sarcopenia were set at $<55 \mathrm{~cm}^{2} / \mathrm{m}^{2}$ for males and $<39 \mathrm{~cm}^{2} / \mathrm{m}^{2}$ for females, according to the international consensus for the definition of cancer cachexia (18). Only the individuals for whom we had sufficient radiological (LSMI) and/or clinical data (BMI, body weight fluctuations within the last six months) in order to be classified as cachectic or not, according to criteria set by Fearon et al. (18), were included in the final analysis (Figure S1).

We furthermore assessed, when available, the LSMI of patients during their treatment with $\mathrm{I}-\mathrm{O}$ in order to investigate any potential correlation of LSMI fluctuations with treatment outcomes. For this purpose, we compared the baseline LSMI values with the LSMI values at the first radiological assessment of each individual after ICI therapy initiation. Patients were categorized according to their changes in LSMI during treatment in a binary fashion according to their median LSMI reduction\% during I-O.

\section{Data collection}

We prospectively collected data on patient [age, gender, smoking status, ECOG performance status (PS), BMI, line of treatment of ICI administration], disease characteristics (histology, organs affected with metastases, PD-L1 status) and baseline albumin values at the timepoint of I-O initiation.

Patients were classified in a dichotomous fashion based on their age ( $<70 v s . \geq 70$ years old), gender (male $v s$. female), PS (0-1 vs. 2), smoking status (smokers or former smokers $v s$. non-smokers), line of treatment of ICI administration (first line $v s$. second or later lines of treatment), brain metastases, liver metastases, bone metastases, disease burden (Low vs. high tumor burden), baseline BMI values ( $<25 v s$. $\geq 25 \mathrm{~kg} / \mathrm{m}^{2}$ ), histology (squamous $v s$. non-squamous), PDL1 status $(<1 \% v s . \geq 1 \%)$ and baseline albumin levels $(<3.5$ $v s . \geq 3.5 \mathrm{~g} / \mathrm{dL})$. PD-L1 expression levels, when available, were evaluated before the initiation of systemic treatment. 36 patients (26 individuals who received pembrolizumab and 10 that received nivolumab) had their samples evaluated using staining with $22 \mathrm{C} 3$ pharmDx assay. The remaining 12 patients with available PD-L1 status had their samples evaluated using Ventana SP142 assay. High disease burden was defined as metastatic spread in $>2$ organs. We decided to use this cut-off since it has been the only clinical factor significantly associated with the development of disease hyper-progression under treatment with ICIs (19). Finally, the cut-off values that were set for baseline albumin levels were the $3.5 \mathrm{~g} / \mathrm{dL}$ (which represents the lower normal limit in our laboratory).

Immune-related adverse events (irAEs) were recorded according to ESMO guidelines (20).

\section{Outcome assessment}

Response to treatment was evaluated according to RECIST 1.1 criteria (21). The images of the patients were reviewed specifically for this study in order to determine response 
assessment according to RECIST 1.1 criteria. Patients were categorized according to their best response to ICIs as having complete response (CR), partial response (PR), stable disease (SD) and progressive disease (PD). Objective response rate (ORR) was defined as the percentage of individuals who achieved CR or PR as best response to treatment and disease control rate (DCR) was defined as the percentage of patients who achieved CR or PR or SD as best response to treatment. Prolonged duration of disease control was defined as absence of disease progression for a time period of $\geq 6$ months amongst the patients who had achieved disease control (CR or PR or SD) at their first radiological assessment after ICI initiation.

Progression-free survival (PFS) was defined as the time from the initiation of ICI until the date of disease progression or death. Overall survival (OS) was defined as the time from the initiation of ICIs to death. Individuals who had not progressed or were still alive at the time of data analysis were censored at the date of last follow-up.

\section{Statistical analysis}

All statistical analyses were performed with SPSS 25.0.0 software (IBM Corp., Armonk, NY, USA). Descriptive statistics were applied to define and categorize nominal and categorical variables. Statistical significance was set at $<0.05$. We furthermore applied Chi-square test to examine any potential associations between the studied variables with ORR and DCR. Kruskal-Wallis test was applied to examine any potential differences in baseline LSMI distributions according to the presence of CCS. In addition, any potential differences in the distributions of LSMI\% changes during I-O with ORR, DCR and duration of disease control $\geq 6$ months were examined with Kruskal-Wallis test.

A univariate binary logistic regression was performed to examine the odds ratios (OR) of the studied parameters on the probability of developing PD as best response to treatment. A multivariate logistic regression was performed for the variables that had reached statistical significance in the univariate analysis.

The Kaplan-Meier method was applied to investigate the effect of the studied variables on PFS and OS. Curves were compared with the log-rank test. In addition, we applied log-rank test in order to examine the effect of baseline cancer cachexia on OS in the subgroup of patients that received $\mathrm{I}-\mathrm{O}$ as first line treatment and in the subgroup of patients that received it as second line treatment. A univariate Cox Regression Analysis was performed to calculate the Hazard Ratios (HR) of age $\geq 70$ years old, PS 2, female gender, squamous histology, bone metastases, liver metastases, brain metastases, PD-L $1<1 \%$, ICI administration as $2^{\text {nd }}$ line of treatment, baseline albumin levels $<3.5 \mathrm{~g} / \mathrm{dL}$ and the presence of baseline CCS on PFS and OS. A multivariate Cox Regression Analysis was performed amongst the variables that had reached statistical significance in the univariate analysis.

Additionally, we applied log-rank test in order to estimate the effect of cancer cachexia on 6 months survival since the initiation of I-O. Six months survival time was used as a cut-off value. Individuals that were alive but had a followup time shorter than 6 months were censored at the time of their last follow-up. Using the 6 months survival time as a cut-off we also performed a univariate Cox regression analysis to estimate the hazard ratio of cancer cachexia on 6 months survival time.

A sample size and power calculation was not conducted because at the time of the initiation of data collection there were no published reports on the effect of cachexia on the outcome of I-O treated cancer patients. Thus, it would have been of no value in this exploratory, hypothesis generated study due to the lack of available data on which to base the required calculations for power calculation.

\section{Results}

\section{Patient characteristics}

A total of 83 patients were included in the analysis. Median follow-up duration was 9.53 months. Patients' characteristics are depicted in detail in Table 1. Median age was 66 years, $84.3 \%$ of patients were male and $92.8 \%$ were active or former smokers. Mean baseline BMI was $26.69 \mathrm{~kg} / \mathrm{m}^{2}$ and $38.6 \%$ of patients had baseline BMI values $<25 \mathrm{~kg} / \mathrm{m}^{2}$.

Most $(79.5 \%)$ patients in our cohort had received ICIs as second line of treatment and the rest as first line treatment. All the patients who received ICIs as second line treatment had previously progressed on a platinum doublet. Only 2 patients $(2.4 \%)$ had received I-O in combination with chemotherapy and the rest as monotherapy. ORR was $20.5 \%$ and $48.2 \%$ of patients experienced PD as best response to treatment. Median PFS and OS were 4.80 and 9.90 months, respectively.

Forty-three patients $(51.8 \%)$ were classified as having baseline CCS at I-O initiation and only 15 patients out of the 54 with evaluable LSMI $(27.8 \%)$ had baseline LSMI values not consistent with sarcopenia (Above LNL). 
Table 1 Baseline patient characteristics

\begin{tabular}{|c|c|c|}
\hline \multirow{2}{*}{ Variable } & \multicolumn{2}{|c|}{ All patients } \\
\hline & $\mathrm{N}$ & $\%$ \\
\hline Number of patients & 83 & \\
\hline Age, median (range) & \multicolumn{2}{|c|}{$66(39-81)$} \\
\hline \multicolumn{3}{|l|}{ Gender } \\
\hline Male & 70 & 84.3 \\
\hline Female & 13 & 15.7 \\
\hline \multicolumn{3}{|l|}{ Performance status } \\
\hline $0-1$ & 65 & 78.3 \\
\hline 2 & 18 & 21.7 \\
\hline \multicolumn{3}{|l|}{ Smoking status } \\
\hline Active or former smokers & 77 & 92.8 \\
\hline Never smokers & 6 & 7.2 \\
\hline \multicolumn{3}{|l|}{ Histology } \\
\hline Squamous & 32 & 38.6 \\
\hline Non-squamous & 51 & 61.4 \\
\hline Mean baseline BMI (SD) & \multicolumn{2}{|c|}{$26.69(4.69)$} \\
\hline \multicolumn{3}{|l|}{ Baseline BMI } \\
\hline$<25 \mathrm{~kg} / \mathrm{m}^{2}$ & 32 & 38.6 \\
\hline$\geq 25 \mathrm{~kg} / \mathrm{m}^{2}$ & 51 & 61.4 \\
\hline \multicolumn{3}{|l|}{ Brain metastases } \\
\hline Yes & 20 & 24.1 \\
\hline No & 63 & 75.9 \\
\hline \multicolumn{3}{|l|}{ Liver metastases } \\
\hline Yes & 23 & 27.7 \\
\hline No & 60 & 72.3 \\
\hline \multicolumn{3}{|l|}{ Bone metastases } \\
\hline Yes & 29 & 34.9 \\
\hline No & 54 & 65.1 \\
\hline \multicolumn{3}{|c|}{ Number of organs with metastatic disease } \\
\hline $1-2$ & 57 & 68.7 \\
\hline$>2$ & 26 & 31.3 \\
\hline \multicolumn{3}{|l|}{ Baseline albumin levels } \\
\hline$\geq 3.5 \mathrm{~g} / \mathrm{dL}$ & 64 & 77.1 \\
\hline$<3.5 \mathrm{~g} / \mathrm{dL}$ & 12 & 14.5 \\
\hline Missing values & 7 & 8.4 \\
\hline
\end{tabular}

Table 1 (continued)
Table 1 (continued)

\begin{tabular}{cc}
\hline \multirow{2}{*}{ Variable } & \multicolumn{2}{c}{ All patients } \\
\cline { 2 - 3 } & $\mathrm{N}$
\end{tabular}

PD-L1 levels

$\begin{array}{lll}<1 \% & 14 & 16.9 \\ 1 \%<\text { PD-L1 }<50 \% & 22 & 26.5 \\ \geq 50 \% & 15 & 18.1 \\ \text { Missing values } & 32 & 38.5\end{array}$

Line of treatment of $\mathrm{ICl}$ administration

$\begin{array}{lll}1^{\text {st }} \text { line } & 17 & 20.5 \\ 2^{\text {nd }} \text { line } & 66 & 79.5\end{array}$

Immunotherapy agent

$54 \quad 65.1$

Pembrolizumab

$26 \quad 31.3$

Atezolizumab

3

3.6

Mode of $\mathrm{ICl}$ administration

Monotherapy

Combination with chemotherapy

$81 \quad 97.6$

$2 \quad 2.4$

Baseline cancer cachexia

Yes

$43 \quad 51.8$

No

$40 \quad 48.2$

Baseline LSMI

Male [mean (SD)]

46.26 (10.07)

Female [mean (SD)]

34.6 (6.74)

Baseline LSMI

$\begin{array}{lll}\text { Below LNV } & 39 & 47.0 \\ \text { Above LNV } & 15 & 18.1 \\ \text { Missing values } & 29 & 34.9\end{array}$

LSMI change during ICI treatment \%, 4.96 (Min: -28.08, Max: median (range)

14.61)

Response to ICls

$\begin{array}{lcc}\text { CR } & 1 & 1.2 \\ \text { PR } & 16 & 19.3 \\ \text { SD } & 26 & 31.3 \\ \text { PD } & 40 & 48.2 \\ \text { Duration of disease control* }(\mathrm{N}=38) & & \\ <6 \text { months } & 10 & 26.3 \\ \geq 6 \text { months } & 28 & 73.7\end{array}$

Table 1 (continued) 
Table 1 (continued)

\begin{tabular}{lcc}
\hline \multirow{2}{*}{ Variable } & \multicolumn{2}{c}{ All patients } \\
\cline { 2 - 3 } & $\mathrm{N}$ & $\%$ \\
\hline Grade III-IV irAEs & 7 & 8.4 \\
Yes & 76 & 91.6 \\
No & $4.80(3.10-6.50)$ \\
PFS (months), median (95\% Cl) & $9.90(6.81-12.98)$ \\
OS (months), median (95\% Cl) & $9.53(6.05-13.01)$ \\
Follow up (months), median (95\% Cl) &
\end{tabular}

*, duration of disease control was calculated amongst the individuals who had achieved PR or SD during their first assessment after $\mathrm{ICl}$ administration and they had sufficient follow-up for 6 months or more. SD, standard deviation; ICl, immune checkpoint inhibitor; LSMI, lumbar skeletal muscle index (at the level of $3^{\text {rd }}$ lumbar vertebra); LNV, lower normal value that was set for males, $55 \mathrm{~cm} / \mathrm{m}^{2}$ and for females, $39 \mathrm{~cm} / \mathrm{m}^{2}$; irAEs, immune related adverse events; PFS, progression free survival; OS, overall survival; $\mathrm{Cl}$, confidence intervals.

Baseline LSMI distributions were significantly different between cachectic and non-cachectic males $(\mathrm{P}=0.001)$ but not females $(\mathrm{P}=0.606)$ (Figure S2).

Twenty-eight patients had evaluable LSMI values at their first evaluation post ICI initiation. Median LSMI percentage change during I-O was $-4.96 \%$ (range, $-28.08 \%$ to $14.61 \%)$. In order to access any potential associations of LSMI fluctuations during ICI treatment we categorized the patients according to their percent LSMI reduction during I-O using as a cut-off the median LSMI reduction during treatment which was $5 \%$.

\section{Effect of the studied variables on response outcomes}

Baseline BMI $<25 \mathrm{~kg} / \mathrm{m}^{2}(\mathrm{P}=0.047)$ and the presence of CCS $(\mathrm{P} \leq 0.001)$ were significantly associated with inferior ORR. The associations of all the studied parameters with ORR are demonstrated in Table S1. Similarly, CCS was significantly associated with reduced DCR $(\mathrm{P} \leq 0.001)$ along with baseline LSMI <Lower Normal Limit (LNL) $(\mathrm{P} \leq 0.001)$, BMI $<25 \mathrm{~kg} / \mathrm{m}^{2}(\mathrm{P}=0.039)$ and metastatic spread in $>2$ organs $(\mathrm{P}=0.034)$. The effect of the analyzed variables on DCR are depicted in Table S2.

The distributions of LSMI percent change during I-O did not significantly differ amongst the individuals who achieved CR or PR as compared to those who experienced
$\mathrm{SD}$ or $\mathrm{PD}(\mathrm{P}=0.446)$ (Figure $\mathrm{S} 3 \mathrm{~A})$. In the same fashion, the distributions of LSMI percent change during I-O did not differ between the individuals with disease control as compared to those who experienced PD $(\mathrm{P} \geq 0.99)$ (Figure S3B) and amongst those who achieved prolonged disease control $\geq 6$ months $v$ s. those who $\operatorname{did}$ not $(\mathrm{P}=0.424)$ (Figure S3C).

In the univariate logistic regression analysis $\mathrm{BMI}$ $<25 \mathrm{~kg} / \mathrm{m}^{2}$ [OR $=2.58$ (95\% CI: 1.04-6.19), $\left.\mathrm{P}=0.041\right]$ and the presence baseline CCS [OR =8.89 (95\% CI: 3.28-24.12), $\mathrm{P} \leq 0.001]$ were significantly associated with increased probability of $\mathrm{PD}$ as best response to ICI treatment (Figure 2A, Table S3). However, in the multivariate analysis, only CCS, OR $=8.11$ (95\% CI: $2.95-22.94, \mathrm{P} \leq 0.001)$ with an area under the curve (AUC) $=0.748$ (95\% CI: 0.640 $0.856)$ independently predicted for increased probability of $\mathrm{PD}$ as best response to treatment (Figure $2 B$ and Table S3).

\section{Effect of the studied variables on survival outcomes}

Patients with baseline CCS experienced significantly inferior PFS (2.36 vs. 7.33 months, $\mathrm{P} \leq 0.001)$ (Figure $3 A$ ) and inferior OS (3.70 vs. 17.93 months, $\mathrm{P} \leq 0.001$ ) (Figure $3 B$ ) as compared to non-cachectic individuals. In a similar fashion, patients with baseline LSMI consistent with sarcopenia had significantly reduced PFS (2.96 vs. 7.96 months, $\mathrm{P}=0.032$ ) (Figure $3 C$ ) and reduced OS (5.43 months vs. not reached, $\mathrm{P}=0.006$ ) (Figure $3 D$ ) as compared to the individuals with baseline LSMI values not consistent with sarcopenia.

However, LSMI reduction $>5 \%$ during $\mathrm{I}-\mathrm{O}$ did not have any effect on PFS (7.96 vs. 7.33 months, $\mathrm{P}=0.193$ ) (Figure $4 A$ ) nor OS (19.20 vs. 14.03 months, $\mathrm{P}=0.400$ ) (Figure $4 B$ ).

The effect of all the other studied covariates on survival outcomes are summarized on Table S4.

The presence of baseline cachexia significantly reduced survival in the subgroup of patients that received I-O as first line treatment (not reached vs. 13.37 months, $\mathrm{P}=0.028$ ) (Figure $5 A$ ) and to the subgroup of patients that received $\mathrm{I}-\mathrm{O}$ as second line treatment (12.70 vs. 3.23 months, $\mathrm{P}=0.003$ ) (Figure 5B). Finally, the presence of baseline cancer cachexia was significantly associated with inferior 6 months survival since the initiation of I-O $(\mathrm{P}<0.001)$ (Figure $\mathrm{S} 4)$.

\section{Univariate and multivariate analysis}

Univariate and multivariate analyses on the effect of the analyzed variables on PFS and OS are summarized in Table 2. 

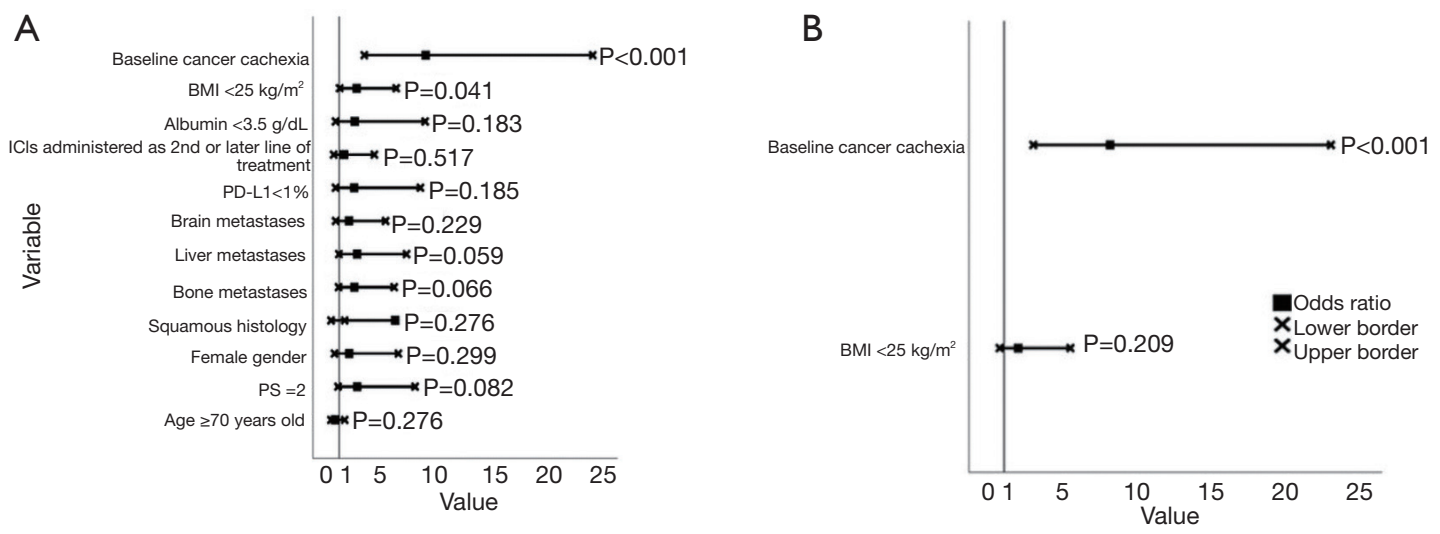

Figure 2 Forest plots depicting the odds ratios of the studied variables on the probability of having disease progression as best response to ICI treatment. (A) Univariate analysis; (B) multivariate analysis. ICI, immune checkpoint inhibitor; BMI, body mass index; PD-L1, programmed death-ligand 1; PS, performance status.
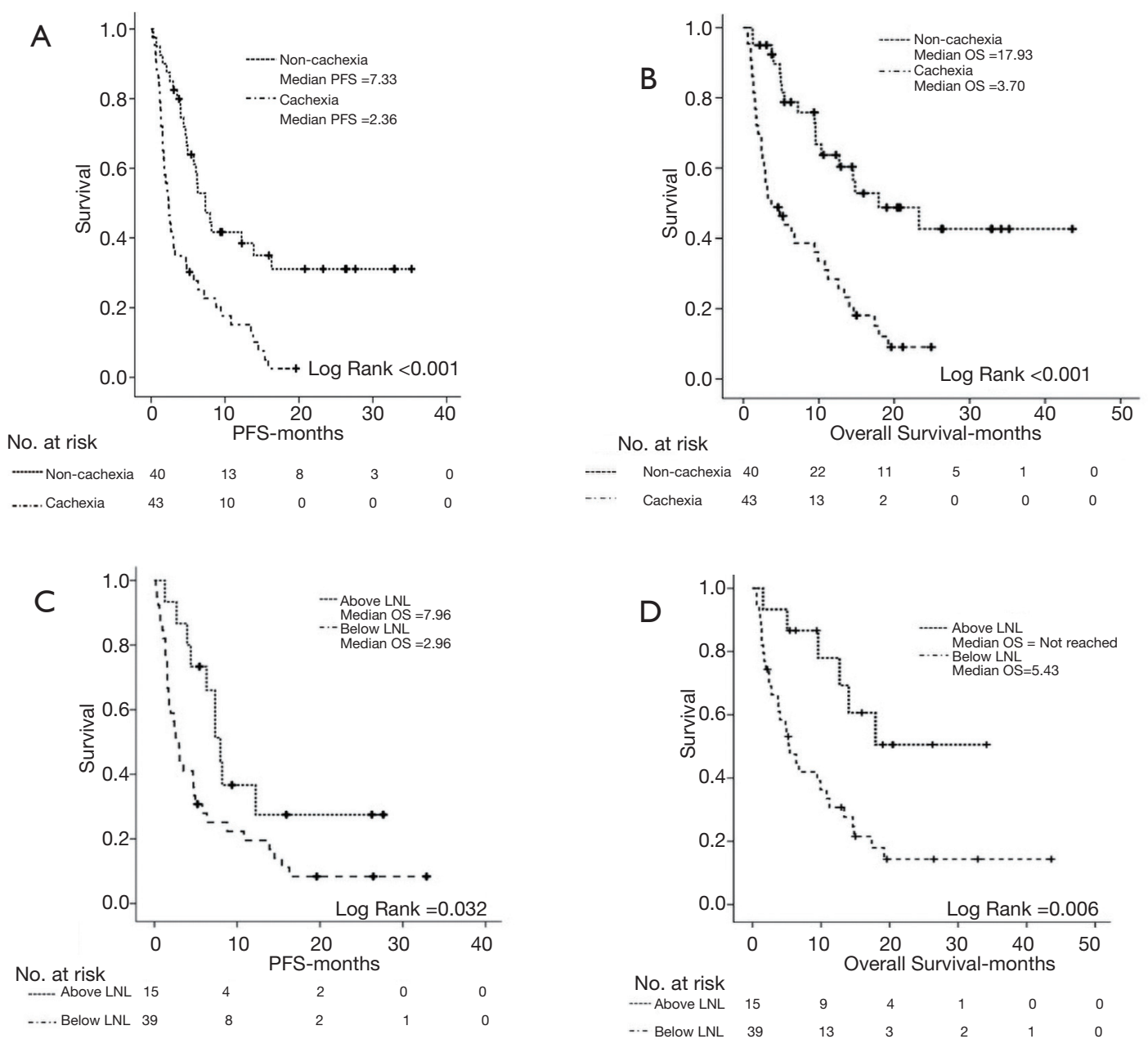

Figure 3 Kaplan-Meier curves depicting the effect of baseline CCS on PFS (A), OS (B) and the effect of baseline LSMI values on PFS (C) and OS (D). CCS, cancer cachexia syndrome; PFS, progression free survival (months); OS, overall survival (months); LSMI, lumbar skeletal muscle index $\left(\mathrm{cm}^{2} / \mathrm{m}^{2}\right)$ (at the level of $3 \mathrm{rd}$ lumbar vertebra); LNL, lower normal limit $\left(55 \mathrm{~cm}^{2} / \mathrm{m}^{2}\right.$ for males and $<39 \mathrm{~cm} / \mathrm{m}^{2}$ for females). 

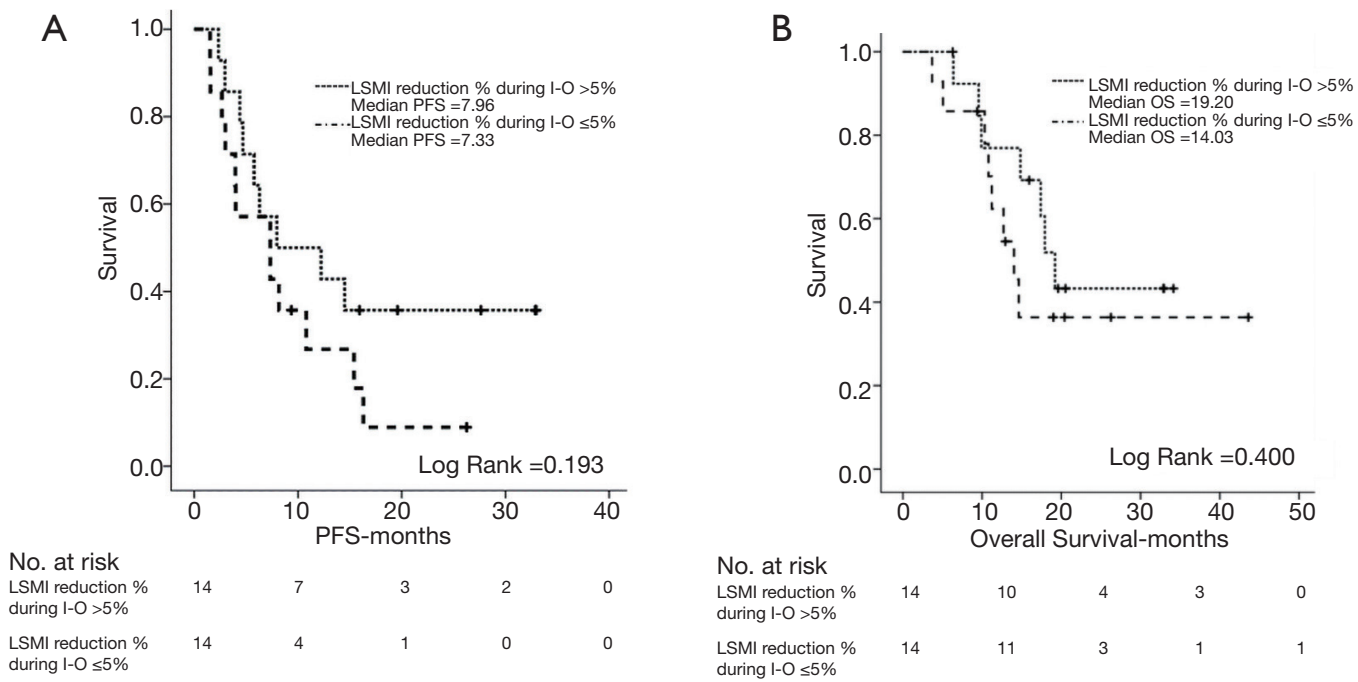

Figure 4 Log-rank test demonstrating the effect of LSMI reduction\% >5 during I-O on PFS (A) and OS (B). LSMI, lumbar skeletal muscle index $\left(\mathrm{cm}^{2} / \mathrm{m}^{2}\right)$ (at the level of $3^{\text {rd }}$ lumbar vertebra); I-O, immunotherapy; PFS, progression free survival; OS, overall survival.
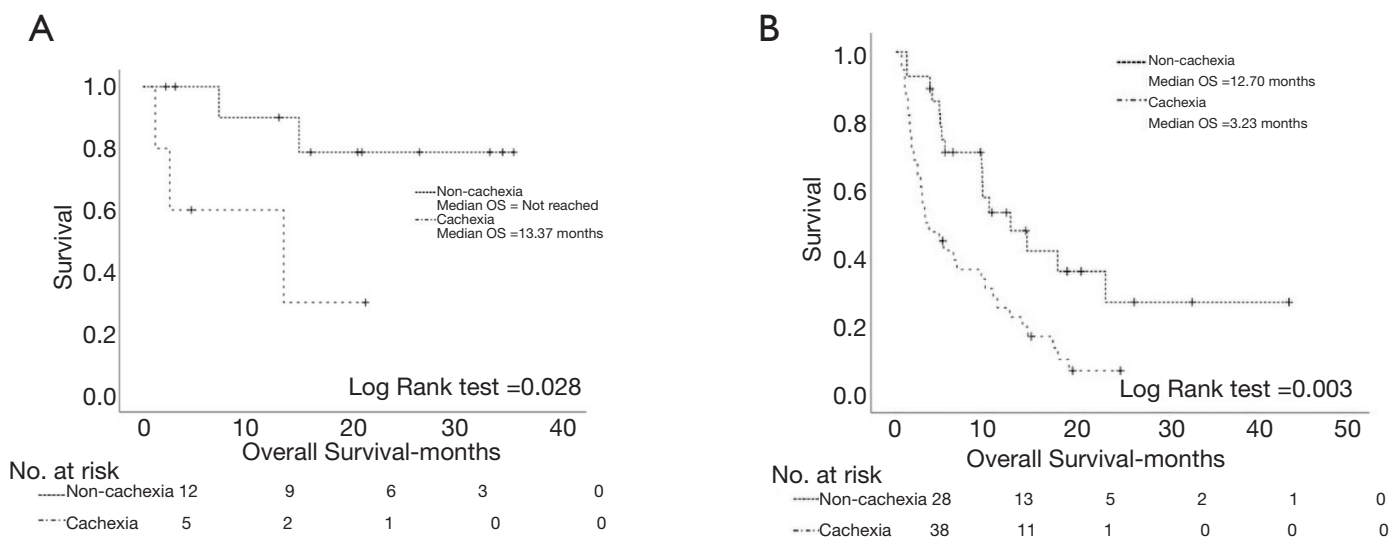

Figure $5 \mathrm{Log}$ rank test demonstrating the effect of cancer cachexia syndrome on overall survival amongst the patients' subgroups that received PD-1/PD-L1 inhibitors as first line treatment (A) and second line treatment (B). OS, overall survival; PD-1, programmed death-1; PD-L1, programmed death ligand 1.

ICI administration as $2^{\text {nd }}$ line of treatment [HR $=2.22(95 \%$ CI: 1.19-4.40), $\mathrm{P}=0.023]$ and baseline CCS $[\mathrm{HR}=2.72(95 \%$ CI: 1.64-4.50), $\mathrm{P} \leq 0.001]$ reached statistical significance in the univariate analysis for PFS. However, in the multivariate analysis only the presence of baseline CCS [HR $=2.49$ (95\% CI: 1.49-4.16), $\mathrm{P} \leq 0.001]$ emerged as an independent predictor for shorter PFS.

In the univariate analysis performance status 2, high disease burden, ICI administration as $2^{\text {nd }}$ line of treatment and baseline CCS were significantly associated with inferior OS. However, in the multivariate analysis, performance status $2[\mathrm{HR}=1.98$ (95\% CI: $1.10-3.58), \mathrm{P}=0.023]$, ICI administration as $2^{\text {nd }}$ line of treatment $[\mathrm{HR}=2.91$ (95\% CI: $1.13-7.49), \mathrm{P}=0.027]$ and the presence of $\mathrm{CCS}[\mathrm{HR}=2.52$ (95\% CI: 1.40-4.55), $\mathrm{P}=0.002]$ independently predicted for shorter survival (Table 2).

In the univariate analysis on the effect of baseline cancer cachexia on the probability of death within 6 months since the initiation of I-O, cancer cachexia was significantly associated with increased risk of death within the first 6 months of I-O [HR $=3.90$ (95\% CI: $1.75-8.70), \mathrm{P}=0.001)$ ] (Figure S4). 
Table 2 Univariate and multivariate analysis using Cox regression method in the whole patient population

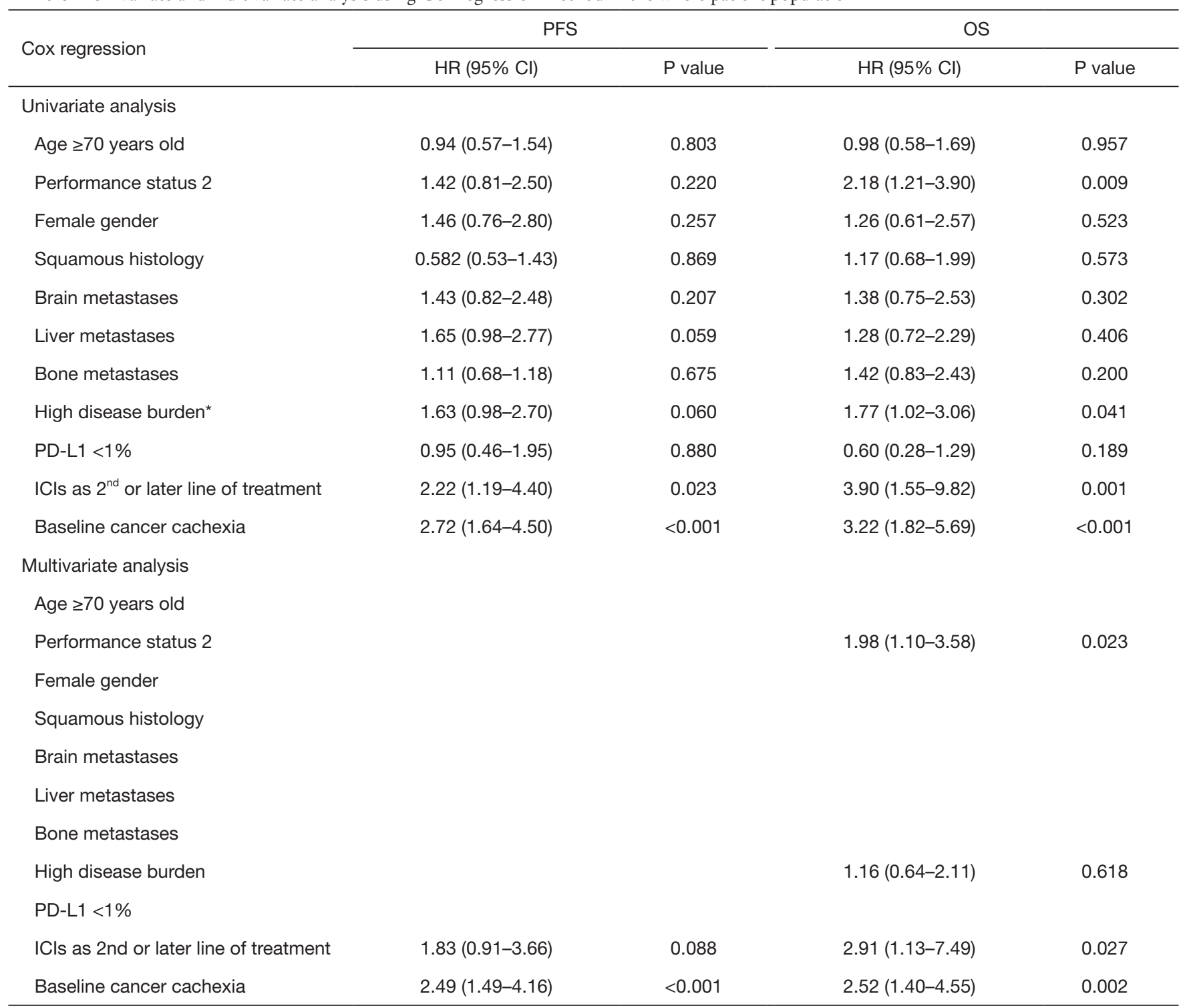

*, high disease burden = metastatic dissemination in more than 2 organs. PFS, progression free survival; OS, overall survival; HR, hazard ratio; ICl, immune checkpoint inhibitor; PD-L1, programmed death ligand-1.

\section{Discussion}

In this prospective study, we demonstrated that cancer cachexia is associated with reduced response rates to PD-1/ PD-L1 inhibitors and that it consists an independent predictor for both inferior PFS and OS. LSMI values below the thresholds for sarcopenia were also associated with inferior survival outcomes.

We decided to categorize the patients of our cohort according to the presence of cancer cachexia based on the criteria set by Fearon et al. (18) since they specifically focus on cancer-related cachexia and take into account pretreatment weight loss, BMI and body composition analysis. Cancer cachexia had a high prevalence amongst the patients of our cohort in accordance with previously published reports (22).

Our results are in accordance with previous published retrospective reports addressing the negative effects of weight loss and reduced muscle mass on I-O outcomes (23-27). Turner et al. (23) performed a pharmacokinetic analysis in patients with NSCLC and melanoma that were treated with pembrolizumab monotherapy. An 
association between rapid baseline plasma clearance $\left(\mathrm{CL}_{0}\right)$ of pembrolizumab and poor OS was reported despite a lack of association between plasma exposure and OS at pembrolizumab doses between 2 and $10 \mathrm{mg} / \mathrm{kg}$. The researchers suggested that the substantial difference in OS was attributed to underlying increased catabolic status caused by CCS, providing indirect evidence that patients with elevated serum protein catabolism are refractory to ICIs. Shiroyama et al. (24) demonstrated in a retrospective cohort of metastatic NSCLC patients that sarcopenia, which was calculated by the psoas muscle index in CT scans, was associated with reduced response rates to PD-1 inhibitors and inferior PFS. Miyawaki et al. (25) and Roch et al. (26) in retrospective cohorts also demonstrated that cachexia, defined as pretreatment weight loss $>5 \%$ in the last 6 months, was an independent predictor of adverse survival outcomes in metastatic NSCLC patients treated with ICIs. Finally, Chu et al. (27) reported that skeletal muscle density is predictive and prognostic in melanoma patients treated with ipilimumab. Our prospective data reinforce these previous retrospective reports on the adverse effects of cachexia and reduced muscle composition on I-O outcomes. However, in contrast to these studies we used a multifaceted definition of cancer cachexia status (18) for the classification of patients of our cohort, since we took into account pretreatment weight loss along with BMI and skeletal muscle index. Importantly, our findings along with the aforementioned retrospective data demonstrate that the presence of cachexia should constitute an additional classification factor in the design of future I-O trials.

Interestingly the distributions of LSMI percent change during I-O did not differ among responders and nonresponders to treatment. In addition, LSMI reduction $>5 \%$ was not associated with inferior PFS or OS in our cohort. These findings are in contrast with the results published by Roch et al. (26) who reported that evolving sarcopenia, defined as reduction in skeletal muscle index more than $5 \%$ during I-O, was associated with adverse survival outcomes. These differences can be attributed to the small number of 28 patients analyzed in our study and the possible selection bias for this subgroup in our cohort. However, body composition fluctuations and their effect on I-O outcomes is an interesting research subject that warrants further investigation.

It has been demonstrated using experimental models that the molecular cascades that govern the pathogenesis of cachexia also negatively affect a wide spectrum of immune antitumor functions (12-16). Furthermore, inhibition of cytokine pathways implicated in the development of cachexia has been shown to invigorate antitumor immune responses (28-30) and combined blockade of specific procachexia mediators and PD-1/PD-L1 axis was also reported to exert synergistic effects $(31,32)$. Thus, the combination of anti-cachexia treatments along with immunotherapies might be necessary for the enhancement of I-O effectiveness and improvement of patient outcomes in patients with cancer cachexia. Nevertheless, further research of the serum or TME of patients with cachexia is required to decipher of the underlying processes that lead to higher rates of ICIs failure in cachectic individuals.

To our knowledge, this is the first prospective study investigating the effect of cancer cachexia on I-O treatment outcomes. In addition, we utilized the definition set by the international consensus for the classification of patients for cancer cachexia. Finally, our study sample consists exclusively from patients with NSCLC who received in their vast majority I-O as PD-1/PD-L1 monotherapy. The main limitations of our study are the relatively small sample size conferring limited statistical power and the fact that we included NSCLC patients receiving ICIs in different lines of therapy and the lack of translational and molecular data.

\section{Conclusions}

Cancer cachexia is an adverse independent factor predicting for poor outcomes in patients with metastatic NSCLC receiving ICIs and should constitute an additional stratification factor in the design of future immunotherapy trials. Finally, further research on the molecular pathogenesis of cachexia could result in the discovery of mechanisms that confer resistance to immunotherapy and the development of novel biomarkers and immunotherapy combinations.

\section{Acknowledgments}

We would like to thank Kyriaki Koutsoudaki and Marina Mavrogianni for their invaluable help in data collection and Sevasti Dara for her assistance in graphic design. Most importantly we would like to thank all the patients who participated in this study and their families.

Funding: None.

\section{Footnote}

Reporting Checklist: The authors have completed the 
REMARK reporting checklist. Available at https://dx.doi. org/10.21037/tlcr-21-460

Data Sharing Statement: Available at https://dx.doi. org/10.21037/tlcr-21-460

Peer Review File: Available at https://dx.doi.org/10.21037/ tlcr-21-460

Conflicts of Interest: All authors have completed the ICMJE uniform disclosure form (available at https://dx.doi. org/10.21037/tlcr-21-460). The authors have no conflicts of interest to declare.

Ethical Statement: The authors are accountable for all aspects of the work in ensuring that questions related to the accuracy or integrity of any part of the work are appropriately investigated and resolved. The study was approved from the Ethics Committee of the University Hospital of Heraklion (ID: 2644) and was conducted according to principles of the declaration of Helsinki (as revised in 2013). Written informed consent was obtained from all patients before enrollment.

Open Access Statement: This is an Open Access article distributed in accordance with the Creative Commons Attribution-NonCommercial-NoDerivs 4.0 International License (CC BY-NC-ND 4.0), which permits the noncommercial replication and distribution of the article with the strict proviso that no changes or edits are made and the original work is properly cited (including links to both the formal publication through the relevant DOI and the license). See: https://creativecommons.org/licenses/by-nc-nd/4.0/.

\section{References}

1. Havel JJ, Chowell D, Chan TA. The evolving landscape of biomarkers for checkpoint inhibitor immunotherapy. Nat Rev Cancer 2019;19:133-50.

2. Sharma P, Hu-Lieskovan S, Wargo JA, et al. Primary, Adaptive, and Acquired Resistance to Cancer Immunotherapy. Cell 2017;168:707-23.

3. Baracos VE, Martin L, Korc M, et al. Cancer-associated cachexia. Nat Rev Dis Primers 2018;4:17105.

4. von Haehling S, Anker SD. Prevalence, incidence and clinical impact of cachexia: facts and numbers-update 2014. J Cachexia Sarcopenia Muscle 2014;5:261-3.

5. Argilés JM, Busquets S, Stemmler B, et al. Cancer cachexia: understanding the molecular basis. Nat Rev Cancer 2014;14:754-62.

6. de Matos-Neto EM, Lima JD, de Pereira WO, et al. Systemic Inflammation in Cachexia - Is Tumor Cytokine Expression Profile the Culprit? Front Immunol 2015;6:629.

7. Peyta L, Jarnouen K, Pinault M, et al. Regulation of hepatic cardiolipin metabolism by TNF $\alpha$ : Implication in cancer cachexia. Biochim Biophys Acta 2015;1851:1490-500.

8. Gioulbasanis I, Patrikidou A, Kitikidou K, et al. Baseline plasma levels of interleukin-8 in stage IV non-small-cell lung cancer patients: relationship with nutritional status and prognosis. Nutr Cancer 2012;64:41-7.

9. Lerner L, Tao J, Liu Q, et al. MAP3K11/GDF15 axis is a critical driver of cancer cachexia. J Cachexia Sarcopenia Muscle 2016;7:467-82.

10. Cuenca AG, Cuenca AL, Winfield RD, et al. Novel role for tumor-induced expansion of myeloid-derived cells in cancer cachexia. J Immunol 2014;192:6111-9.

11. Chen DS, Mellman I. Oncology meets immunology: the cancer-immunity cycle. Immunity 2013;39:1-10.

12. Bertrand F, Montfort A, Marcheteau E, et al. TNFa blockade overcomes resistance to anti-PD-1 in experimental melanoma. Nat Commun 2017;8:2256.

13. Flint TR, Janowitz T, Connell CM, et al. Tumor-Induced IL-6 Reprograms Host Metabolism to Suppress Antitumor Immunity. Cell Metab 2016;24:672-84.

14. Jin L, Tao H, Karachi A, et al. CXCR1- or CXCR2modified CAR T cells co-opt IL-8 for maximal antitumor efficacy in solid tumors. Nat Commun 2019;10:4016.

15. Roth P, Junker M, Tritschler I, et al. GDF-15 contributes to proliferation and immune escape of malignant gliomas. Clin Cancer Res 2010;16:3851-9.

16. Gabrilovich DI, Nagaraj S. Myeloid-derived suppressor cells as regulators of the immune system. Nat Rev Immunol 2009;9:162-74.

17. Planchard D, Popat S, Kerr K, et al. Metastatic nonsmall cell lung cancer: ESMO Clinical Practice Guidelines for diagnosis, treatment and follow-up. Ann Oncol 2018;29:iv192-237. Erratum in: Ann Oncol 2019;30:863-70.

18. Fearon K, Strasser F, Anker SD, et al. Definition and classification of cancer cachexia: an international consensus. Lancet Oncol 2011;12:489-95.

19. Ferrara R, Mezquita L, Texier M, et al. Hyperprogressive Disease in Patients With Advanced Non-Small Cell Lung Cancer Treated With PD-1/PD-L1 Inhibitors or With Single-Agent Chemotherapy. JAMA Oncol 2018;4:1543-52. 
20. Haanen JBAG, Carbonnel F, Robert C, et al. Management of toxicities from immunotherapy: ESMO Clinical Practice Guidelines for diagnosis, treatment and followup. Ann Oncol 2017;28:iv119-42.

21. Eisenhauer EA, Therasse P, Bogaerts J, et al. New response evaluation criteria in solid tumours: revised RECIST guideline (version 1.1). Eur J Cancer 2009;45:228-47.

22. Tan BH, Fearon KC. Cachexia: prevalence and impact in medicine. Curr Opin Clin Nutr Metab Care 2008;11:400-7.

23. Turner DC, Kondic AG, Anderson KM, et al. Pembrolizumab Exposure-Response Assessments Challenged by Association of Cancer Cachexia and Catabolic Clearance. Clin Cancer Res 2018;24:5841-9.

24. Shiroyama T, Nagatomo I, Koyama S, et al. Impact of sarcopenia in patients with advanced non-small cell lung cancer treated with PD-1 inhibitors: A preliminary retrospective study. Sci Rep 2019;9:2447.

25. Miyawaki T, Naito T, Kodama A, et al. Desensitizing Effect of Cancer Cachexia on Immune Checkpoint Inhibitors in Patients With Advanced NSCLC. JTO Clin Res Rep 2020. doi: 10.1016/j.jtocrr.2020.100020

26. Roch B, Coffy A, Jean-Baptiste S, et al. Cachexia - sarcopenia as a determinant of disease control

Cite this article as: Rounis $\mathrm{K}$, Makrakis D, Tsigkas AP, Georgiou A, Galanakis N, Papadaki C, Monastirioti A, Vamvakas L, Kalbakis K, Vardakis N, Kontogianni M, Gioulbasanis I, Mavroudis D, Agelaki S. Cancer cachexia syndrome and clinical outcome in patients with metastatic nonsmall cell lung cancer treated with PD-1/PD-L1 inhibitors: results from a prospective, observational study. Transl Lung Cancer Res 2021;10(8):3538-3549. doi: 10.21037/tlcr-21-460 rate and survival in non-small lung cancer patients receiving immune-checkpoint inhibitors. Lung Cancer 2020;143:19-26.

27. Chu MP, Li Y, Ghosh S, et al. Body composition is prognostic and predictive of ipilimumab activity in metastatic melanoma. J Cachexia Sarcopenia Muscle 2020;11:748-55.

28. Maecker H, Varfolomeev E, Kischkel F, et al. TWEAK attenuates the transition from innate to adaptive immunity. Cell 2005;123:931-44.

29. Rautela J, Dagley LF, de Oliveira CC, et al. Therapeutic blockade of activin-A improves NK cell function and antitumor immunity. Sci Signal 2019;12:aat7527.

30. Tinoco R, Carrette F, Barraza ML, et al. PSGL-1 Is an Immune Checkpoint Regulator that Promotes T Cell Exhaustion. Immunity 2016;44:1190-203.

31. Li J, Xu J, Yan X, et al. Targeting Interleukin-6 (IL-6) Sensitizes Anti-PD-L1 Treatment in a Colorectal Cancer Preclinical Model. Med Sci Monit 2018;24:5501-8.

32. Kaplanov I, Carmi Y, Kornetsky R, et al. Blocking IL-1 $\beta$ reverses the immunosuppression in mouse breast cancer and synergizes with anti-PD-1 for tumor abrogation. Proc Natl Acad Sci U S A 2019;116:1361-9. 


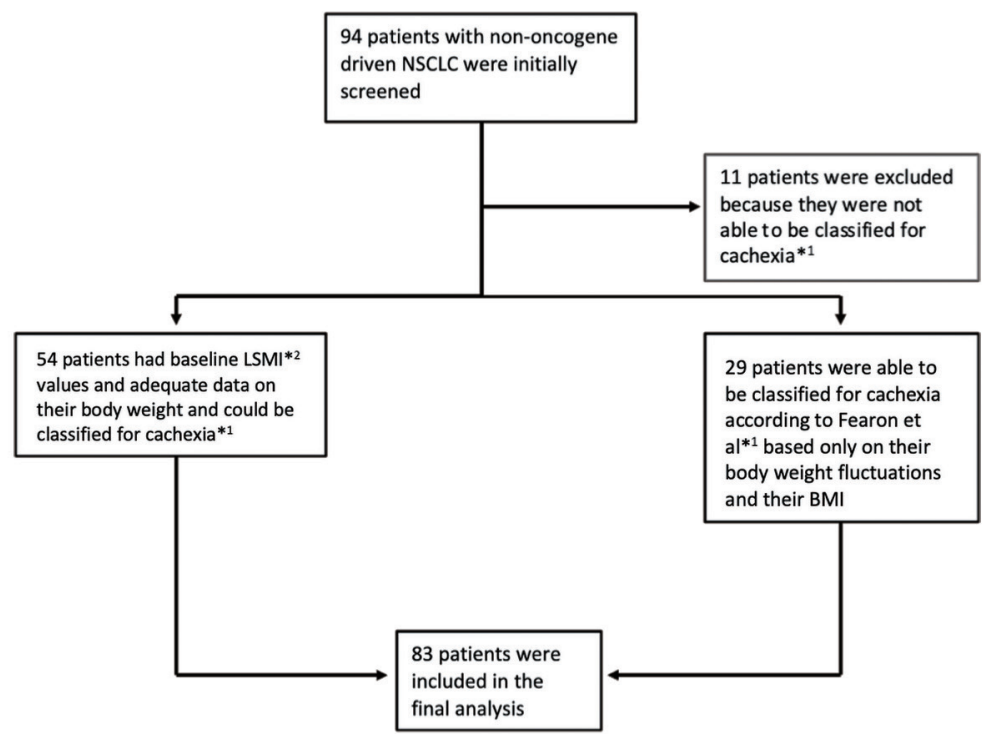

Figure S1 Flow chart of our study. ${ }^{* 1}$, classification for cachexia was conducted according to the criteria by Fearon et al. (18). ${ }^{2}$, LSMI: Lumbar Skeletal Muscle Index.

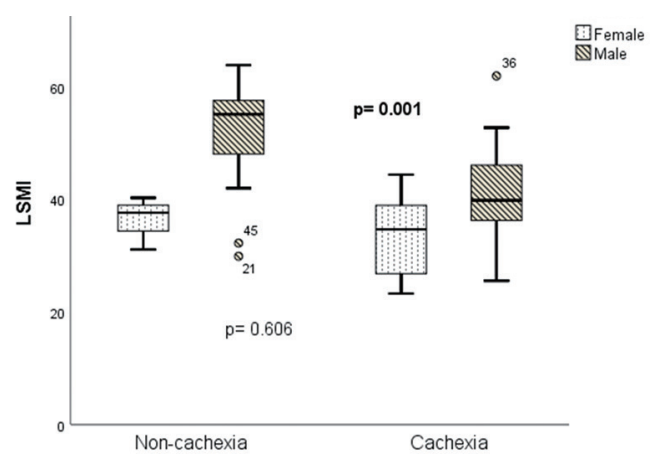

Figure S2 Kruskal-Wallis test examining potential differences in the distributions of baseline LSMI values between cachectic vs. non-cachectic males and cachectic $v$ s. non-cachectic females. 

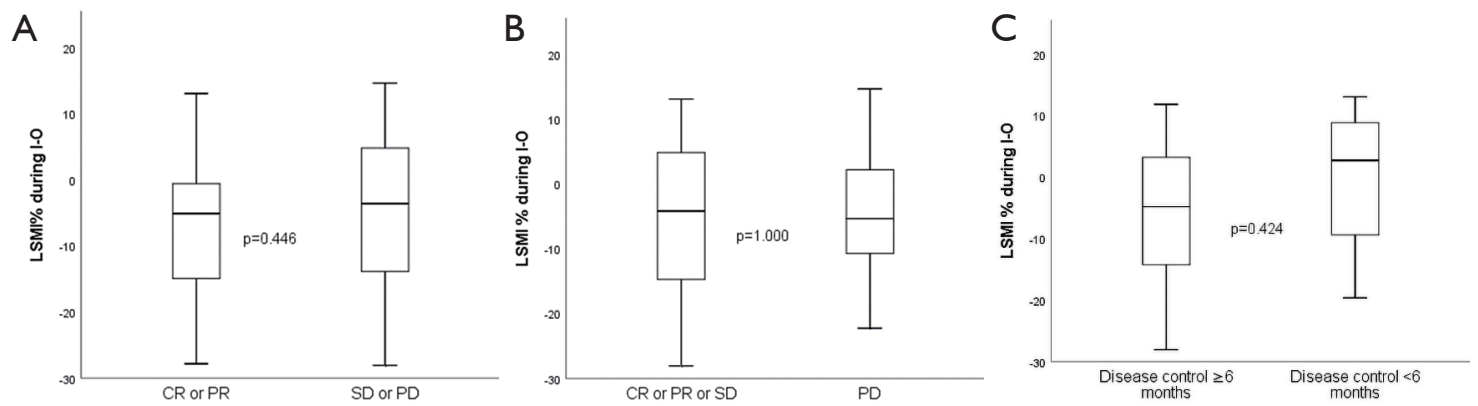

Figure S3 Kruskal-Wallis test investigating any potential difference in the distributions of LSMI change \% during I-O. (A) Between patients who had CR or PR vs. those who experience SD or PD. (B) Between patients who had CR or PR or PD vs. those who experienced PD. (C) Between individuals who achieved prolonged disease control for $\geq 6$ months $v s$. those who did not.

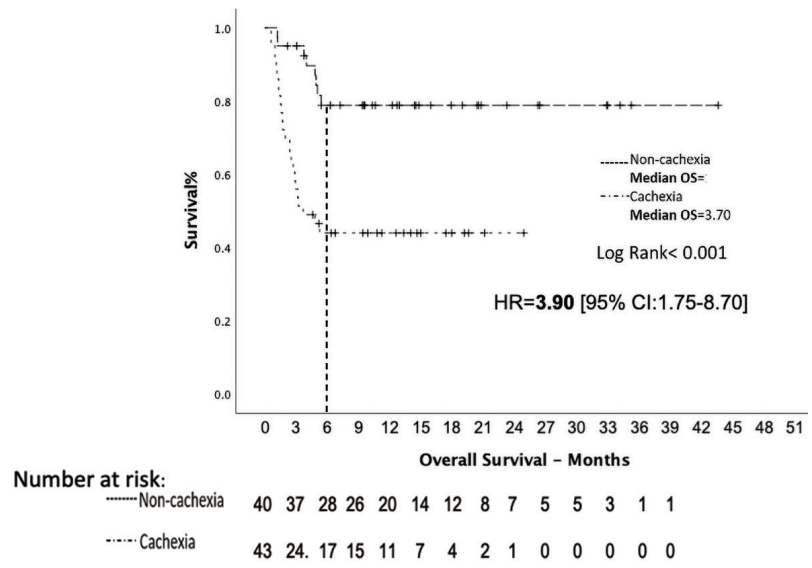

Figure S4 Log-rank test demonstrating the effect of cancer cachexia syndrome on 6 months survival.

Table S1 Effect of the studied variables on response rates

\begin{tabular}{|c|c|c|c|c|}
\hline Variable & $\mathrm{N}=83$ & CR or PR & SD or PD & $\mathrm{P}$ value (chi-square test, $95 \% \mathrm{Cl}$ ) \\
\hline \multicolumn{5}{|l|}{ Age } \\
\hline$<70$ years old & 51 & 12 & 39 & 0.385 \\
\hline$\geq 70$ years old & 32 & 5 & 27 & \\
\hline \multicolumn{5}{|l|}{ Gender } \\
\hline Female & 13 & 3 & 10 & \\
\hline \multicolumn{5}{|c|}{ Performance status } \\
\hline $0-1$ & 65 & 14 & 51 & 0.650 \\
\hline 2 & 18 & 3 & 15 & \\
\hline
\end{tabular}

Table S1 (continued) 
Table S1 (continued)

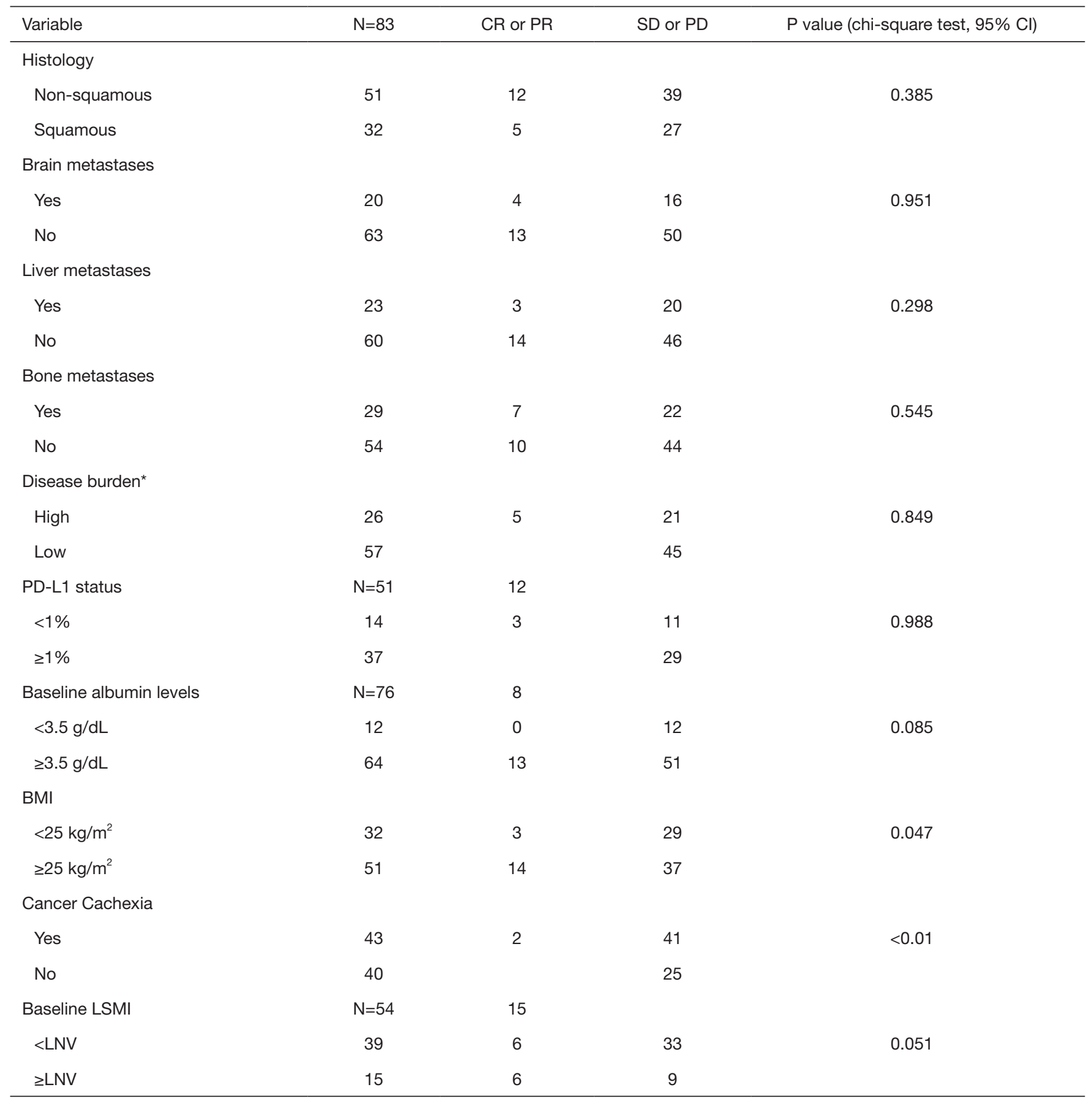

*, high disease burden was defined as $>2$ organs with metastatic spread. LSMI, lumbar skeletal muscle index (at the level of $3^{\text {rd }}$ lumbar vertebra), LNV, lower normal value that was set for males $=55 \mathrm{~cm} / \mathrm{m}^{2}$ and for females $=39 \mathrm{~cm} / \mathrm{m}^{2}$. 
Table S2 Effect of the studied variables on disease control (CR or PR or SD) rates.

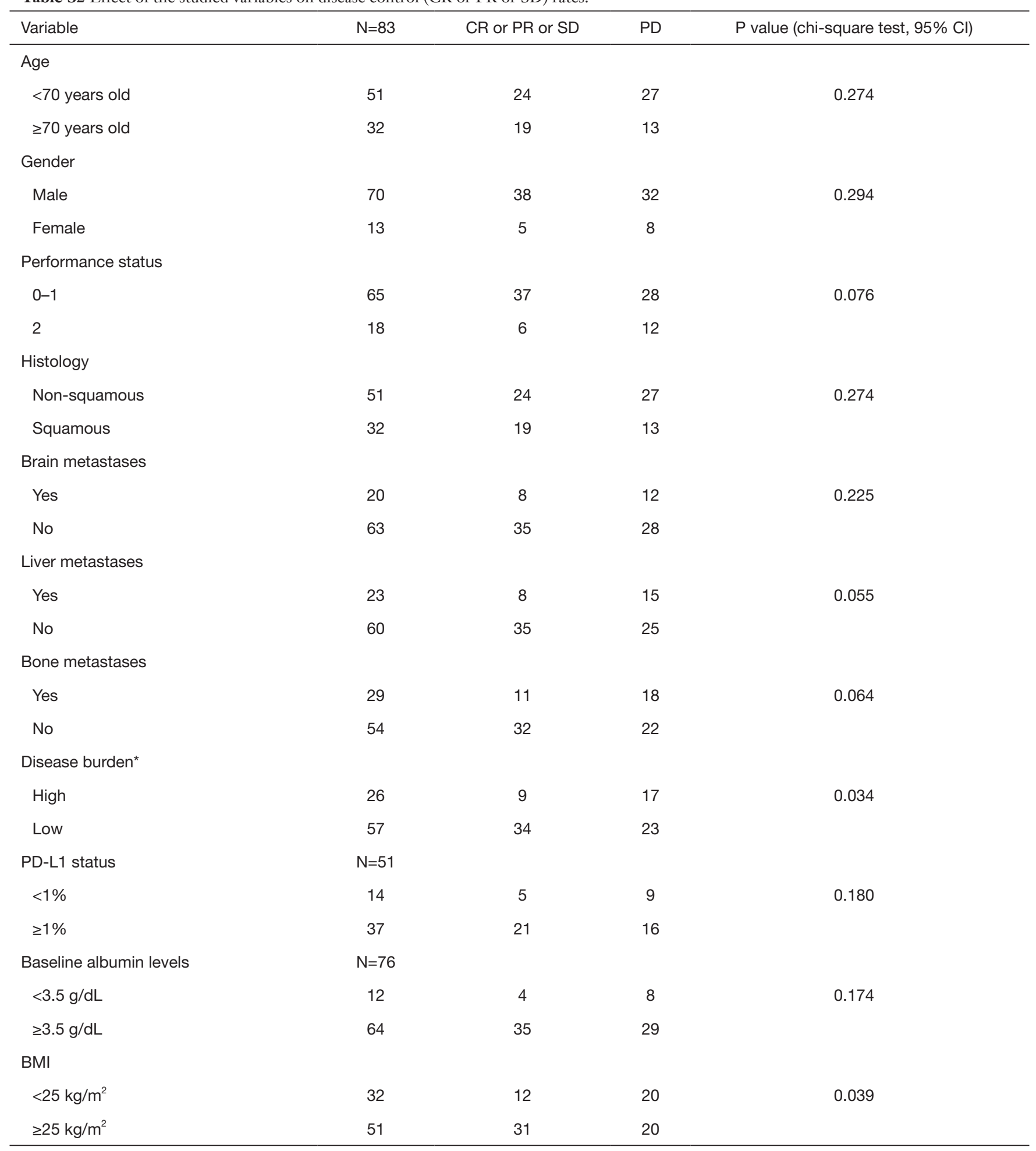

Table S2 (continued) 
Table S2 (continued)

\begin{tabular}{lcccc}
\hline Variable & $\mathrm{N}=83$ & CR or PR or SD & PD & P value (chi-square test, 95\% Cl) \\
\hline Cancer Cachexia & 43 & 12 & 31 & $<0.01$ \\
Yes & 40 & 31 & 9 & $<0.01$ \\
No & $\mathrm{N}=54$ & & & \\
Baseline LSMI & 39 & 13 & 26 & 2 \\
$\quad$ L LNV & 15 & 13 & & \\
\hline LNV & & & & \\
\hline
\end{tabular}

*, high disease burden was defined as $>2$ organs with metastatic spread. LSMI, lumbar skeletal muscle index (at the level of $3^{\text {rd }}$ lumbar vertebra), LNV, lower normal value that was set for males $=55 \mathrm{~cm} / \mathrm{m}^{2}$ and for females $=39 \mathrm{~cm} / \mathrm{m}^{2}$.

Table S3 Univariate and multivariate logistic regression on the odds ratio (OR) of the analyzed covariates on the probability of developing disease progression (PD) as response to treatment with ICIs

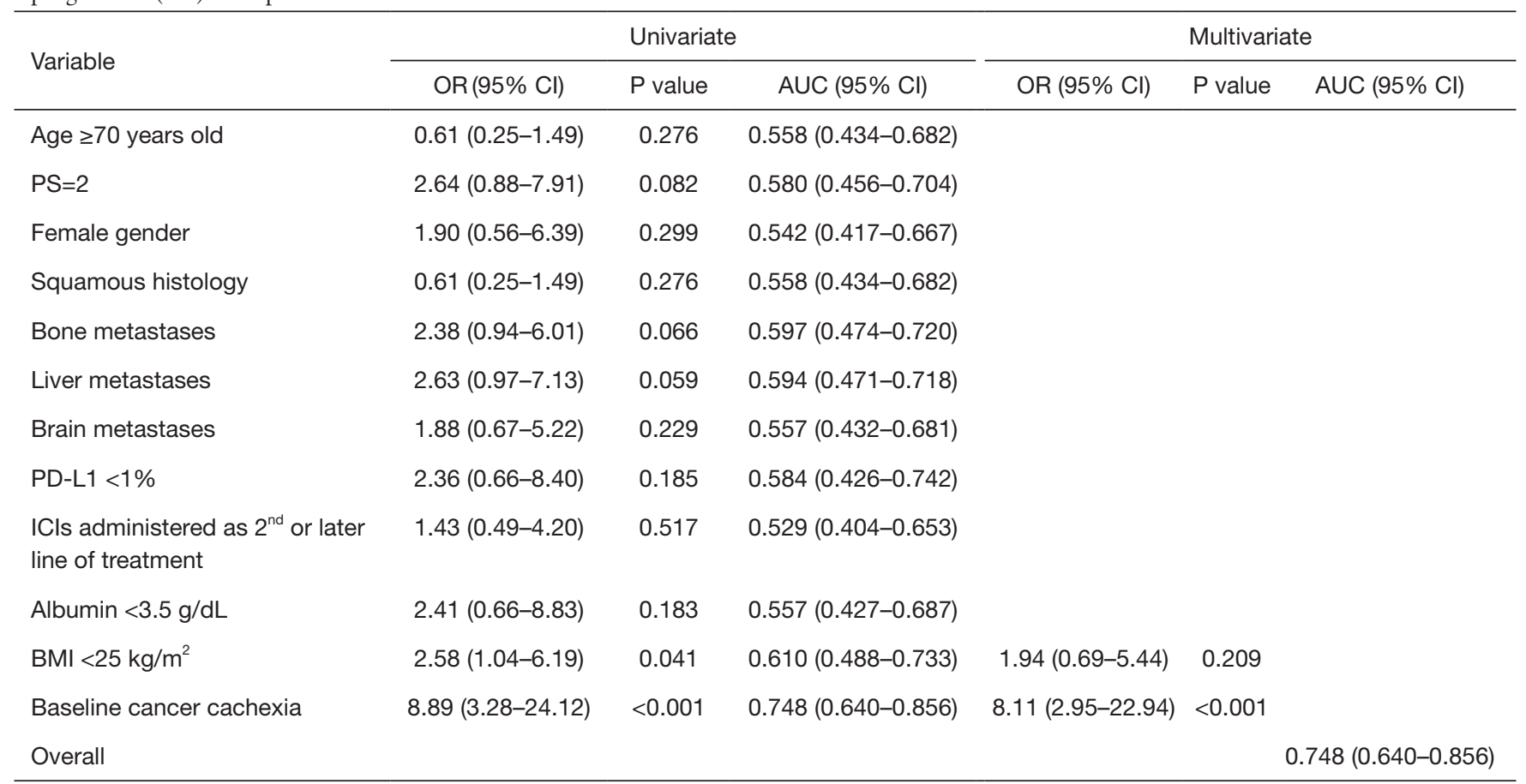

OR, Odds Ratio; AUC, Area under the curve; PS, Performance status. 
Table S4 Log-rank test on the effect of the studied variables on PFS and OS ( $n=83$ )

\begin{tabular}{|c|c|c|c|c|}
\hline Variable & Median PFS (Months) & $P$ value (log-rank test) & Median OS (Months) & $P$ value (log-rank test) \\
\hline$<70$ years old & 4.00 & 0.803 & 9.47 & 0.957 \\
\hline$\geq 70$ years old & 7.17 & & 12.70 & \\
\hline \multicolumn{5}{|l|}{ Gender } \\
\hline Female & 2.10 & & 9.43 & \\
\hline \multicolumn{5}{|c|}{ Performance Status } \\
\hline $0-1$ & 5.77 & 0.217 & 12.60 & 0.008 \\
\hline 2 & 2.40 & & 3.17 & \\
\hline Non-squamous & 3.00 & & 9.90 & \\
\hline \multicolumn{5}{|l|}{ BMI } \\
\hline$<25 \mathrm{~kg} / \mathrm{m}^{2}$ & 2.53 & 0.153 & 4.00 & 0.273 \\
\hline$\geq 25 \mathrm{~kg} / \mathrm{m}^{2}$ & 6.20 & & 10.33 & \\
\hline \multicolumn{5}{|c|}{ Line of treatment of $\mathrm{ICl}$ administration } \\
\hline $1^{\text {st }}$ line & 13.80 & 0.019 & Not reached & 0.002 \\
\hline $2^{\text {nd }}$ or later lines & 4.40 & & 9.43 & \\
\hline \multicolumn{5}{|l|}{ Brain metastases } \\
\hline No & 3.23 & & 12.70 & \\
\hline \multicolumn{5}{|l|}{ Liver metastases } \\
\hline Yes & 2.10 & 0.056 & 6.77 & 0.405 \\
\hline No & 5.77 & & 10.80 & \\
\hline \multicolumn{5}{|l|}{ Disease burden* } \\
\hline High & 2.53 & 0.057 & 4.83 & 0.038 \\
\hline Low & 4.93 & & 13.37 & \\
\hline \multicolumn{5}{|c|}{ Baseline albumin levels } \\
\hline$<3.5 \mathrm{~g} / \mathrm{dL}$ & 1.77 & 0.008 & 2.40 & 0.017 \\
\hline$\geq 3.5 \mathrm{~g} / \mathrm{dL}$ & 5.77 & & 11.23 & \\
\hline
\end{tabular}

Table S4 (continued) 
Table S4 (continued)

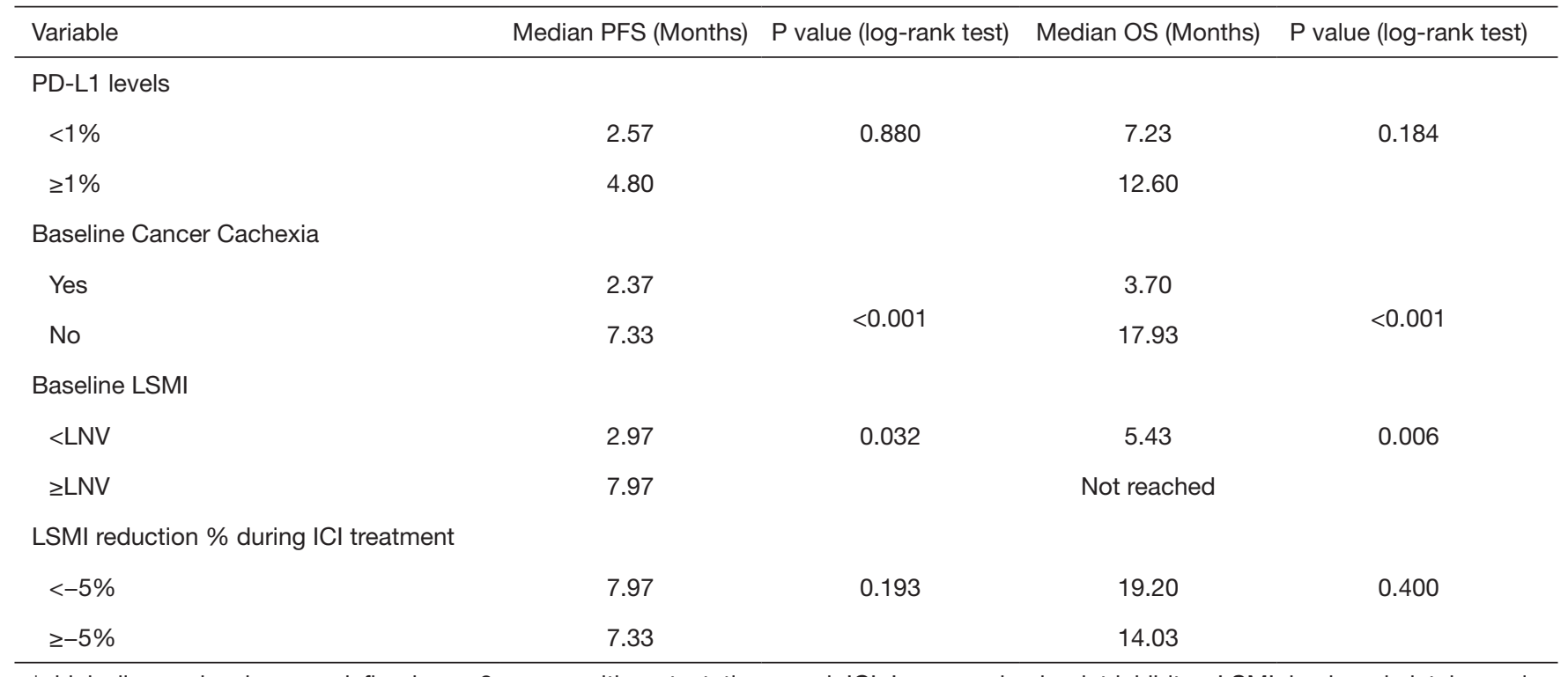

${ }^{*}$, high disease burden was defined as $>2$ organs with metastatic spread. ICl, Immune checkpoint inhibitor; LSMI, lumbar skeletal muscle index (at the level of $3^{\text {rd }}$ lumbar vertebra); LNV, lower normal value that was set for males $=55 \mathrm{~cm} / \mathrm{m}^{2}$ and for females $=39 \mathrm{~cm} / \mathrm{m}^{2}$. 